\section{Histological Interpretation of Helicobacter pylori Density Relevant to Gastric Pathology and its Bias}

\section{Chi Min Shih ${ }^{1,3,5 *}$, Wen Yu Chueh ${ }^{2}$, Tai Tien Chung ${ }^{3}$, Chien Kuo Liu ${ }^{4}$, Chun Chieh Liu ${ }^{1}$ and Chia Ming Lai ${ }^{6 *}$}

${ }^{1}$ Department of Pathology, Chia Yi Hospital, Ministry of Health and Welfare, Chiayi, Taiwan

${ }^{2}$ Department of Pathology, Feng Yuan Hospital, Ministry of Health and Welfare, Taichung, Taiwan

${ }^{3}$ Department of Gastroenterology, Chia Yi Hospital, Ministry of Health and Welfare, Chiayi, Taiwan

${ }^{4}$ Department of Gastroenterology, St. Joseph's Hospital, Yunlin, Taiwan

${ }^{5}$ Depart of Pathology, St. Joseph's Hospital, Yunlin, Taiwan

${ }^{6}$ Department of Gastroenterology, Chien Yu Hospital, Kaohsiung, Taiwan

\begin{abstract}
A lot of articles related to Helicobacter pylori (HP) have been produced from bench to bedside about active gastritis, gastric ulcer, duodenal ulcer and even gastric malignancies. Thanks to the efforts of eradication of HP, the necessity of accepting surgical intervention for aggravated peptic ulcer has been reduced obviously. The battle between human being and HP keeps going on from eradication of HP infection to optimal antibiotic administration to prevent progressive drug resistance. Now we will bring out our differentiated pathologic findings and long term clinical experience to deal with the limitations of histological examination and correlate with real clinical situation, moreover make evidence based therapeutic choice.

Keywords: Gastro duodenal mucosa; Giemsa stain; Helicobacter pylori; Immunohistochemical stain
\end{abstract}

\section{Introduction}

Campylobacter pylori (Helicobacter pylori) has been identified as a gastric pathogen by Barry J Marshal and J Robin Warren since 1982 [1]. Helicobacter pylori (HP) indwells in the mucous film on gastric mucosal surface and superficial gastric pits to escape from high acidity in

${ }^{*}$ Corresponding authors: Chi Min Shih, Department of pathology, Chia Yi Hospital, Ministry of Health and Welfare, Chiayi, Taiwan, Tel: +886 963023378; E-mail: sgmluca@gmail.com

Chia Ming Lai, Department of Gastroenterology, Chie Yu Hospital, Kaohsiung, Taiwan, Tel: +886 963023378; E-mail: ndmc_4518@yahoo.com.tw

Citation: Shih CM, Chueh WY, Chung TT, Liu CK, Liu CC, et al. (2017) Histological Interpretation of Helicobacter pylori Density Relevant to Gastric Pathology and its Bias. J Cytol Tissue Biol 4: 014.

Received: February 14, 2017; Accepted: April 19, 2017; Published: April 30, 2017 stomach [1-4]. In our observation, HP infection can be found from gastric cardia to pylorus but very rarely found in duodenum even in the gastric metaplasia site or duodenum, though Barrett's esophagus and duodenal bulb to descending duodenum could find HP mentioned in the Maastricht V/Florence Consensus Report [4]. Costs, sensitivity and specificity of various detection methods, check up facility and techniques for HP detection are well documented [5-9]. A histopathologic exam for HP density needs precise interpretation, or it will affect the sensitivity and specificity of HP detection $[5,10,11]$. Here in we would like to offer some findings and discussion for sharing experience.

\section{Material and Methods}

The HP density in gastric pits and on mucosal surface are detected through H \& E stain (Figures 1A \& 1B), Giemsa stain (Figures 2A 2C) (Giemsa's stain solution of Muto Pure Chemicals Co., Ltd) or Immunohistochemical (IHC) stain (primary antibody: Zytomed Rabbit anti-Helicobacter pylori polyclonal antibody, and Bond Polymer Refine Detection kit of Leica Co.) under microscopy. H \& E stain necessitates 400X high power view to confirm HP density. Although Giemsa stain can enhance the contrast of HP staining, HP infection must be checked at 200X to 400X high power field to distinguish the shape of curved rod or coccoid form, unlike the IHC staining that brown signals of HP density can be read at 100X to 200X magnifications without difficulty.

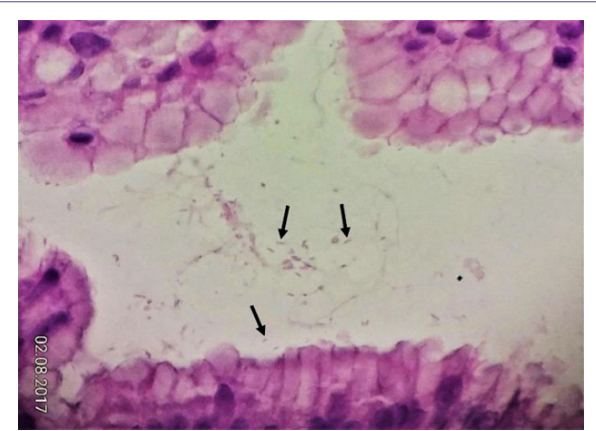

Figure 1A: Low density of curved rods (arrows) can be found in superficial gastric pits (H\& E, 600X).

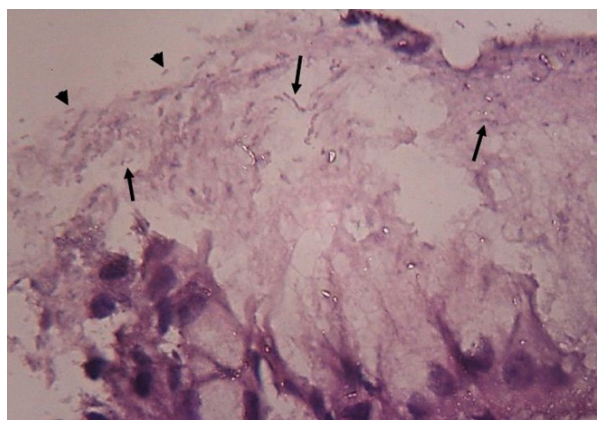

Figure 1B: Medium HP density is present in (arrows) or on(arrow heads) the mucus film of mucosal surface ( $\mathrm{H} \& \mathrm{E}, 1000 \mathrm{X})$. 


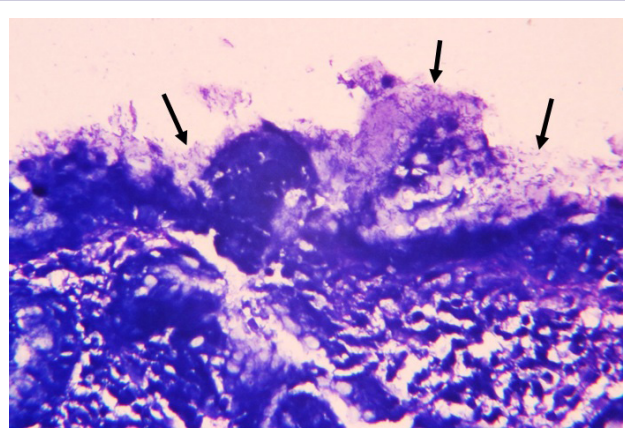

Figure 2A: High HP density can be detected by Giemsa stain on mucosal surface and within its mucous coating (arrows (400X).

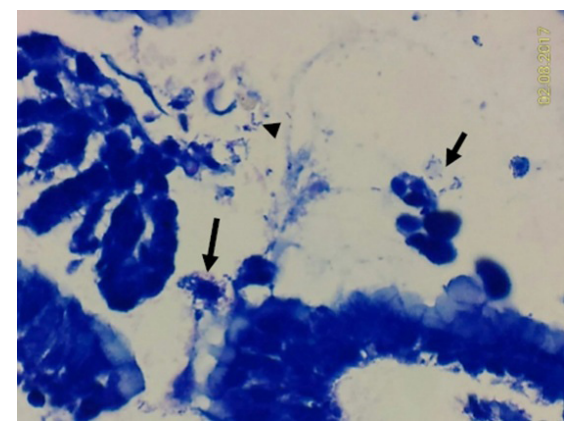

Figure 2B: Curved rods in mucus (short arrow) or coccoid form (arrow head) can be seen on mucosal surface, and suspected contaminated bacterial cluster (arrow) also present (Giemsa stain, 600X).

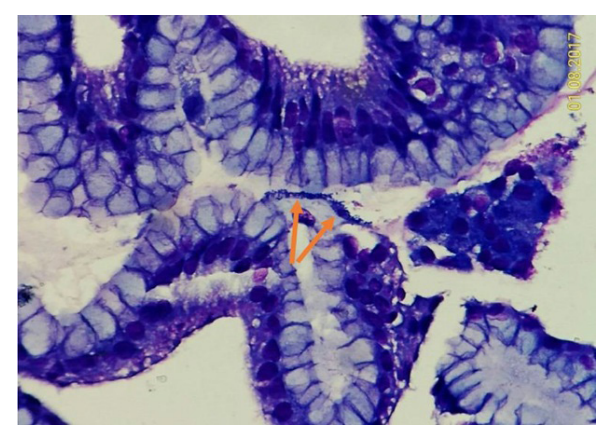

Figure 2C: Very rare HP infection could be found on mucosa of fundic gland polyp. A small bacterial cluster (arrows) on the mucosal surface to be oral contamination or not? (Giemsa stain, 400X).

The gastric tissue can also be put in Campylobacter Like Organism (CLO) test kit to detect the presence of HP. The HP densities can be categorized into high, medium, low and trace levels (Figures 3A-3C).

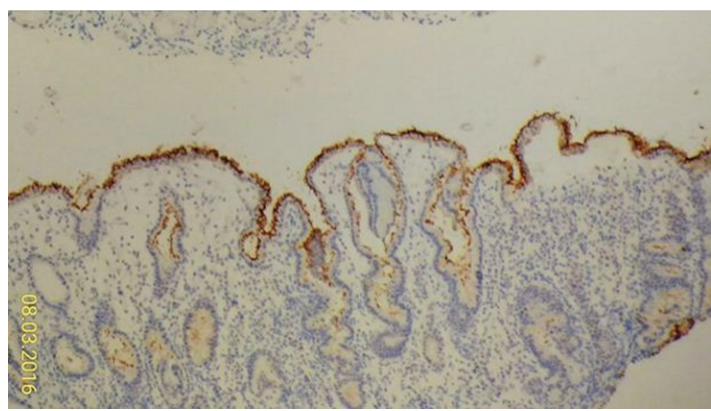

Figure 3A1: High HP density (brown color).

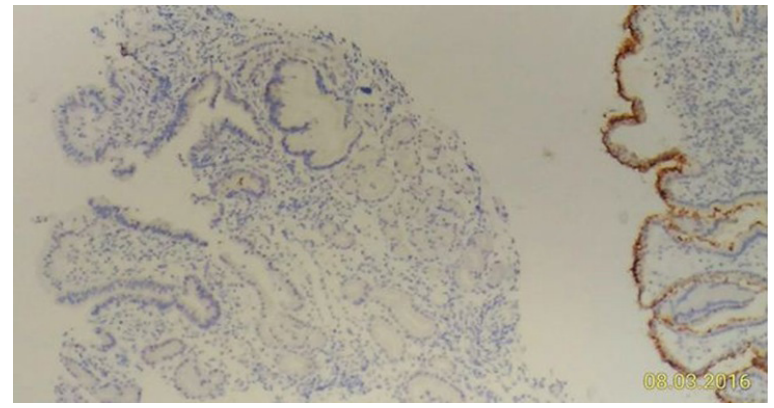

Figure 3A2: Patchy HP distribution observable by devoid of HP density at nearby mucosa without different specific tissue change (left part).

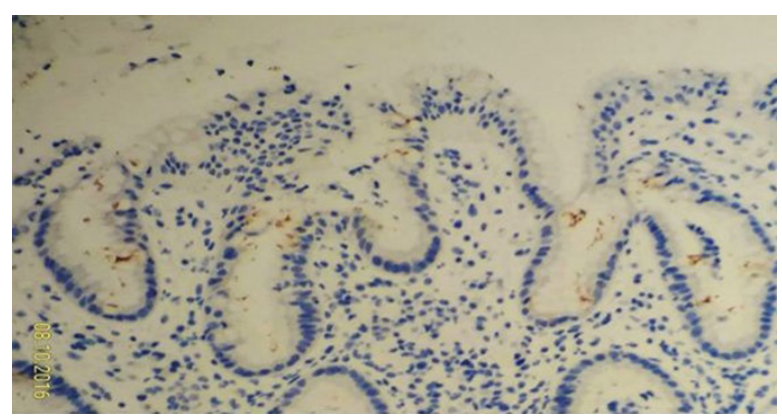

Figure 3B: Low HP density.

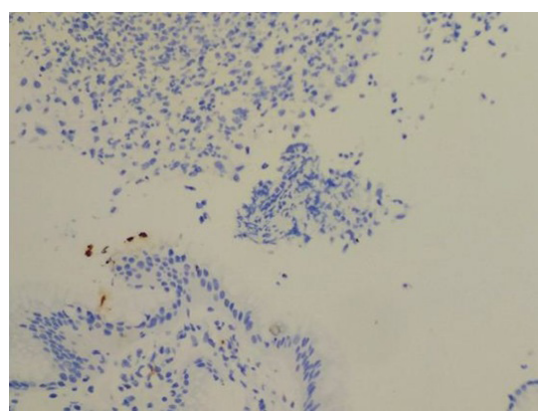

Figure 3C: Trace HP density on mucosa at a case of gastric ulcer (uppe part) need at least 200X magnification to identify it (lower part) (HP IHC stain, 400X).

\section{Results and Discussion}

Presence of HP density is frequently associated with erosive gastritis, gastric ulcer, active gastritis [11,12], but not vice versa, nor absolute proportional relationship (Figure 3C). The inflammatory situation may be affected by individual genetic factor at least [13]. In our observation, atrophic gastritis and intestinal metaplasia do not exclusively coexist with HP infection in submitted mucosal tissue specimen. Incidental use of antibiotics within 3 weeks before histologic exam of HP infection may lower the positive rate. HP infection rate seems decreased among some hospitals in Taiwan like some other areas in the world $[5,14]$.

The fundic glands polyp have markedly lower HP densities (Figure 2C) comparing with those of the remaining gastric biopsy specimens in the same hospital [15], like the rarity of intestinal metaplasia in fundic gland polyp. Intestinal metaplasia (Figure 4) and fundic gland polyp will push aside the HP density, and the biopsies on these lesions without HP density should not exclude the presence of 
Citation: Shih CM, Chueh WY, Chung TT, Liu CK, Liu CC, et al. (2017) Histological Interpretation of Helicobacter pylori Density Relevant to Gastric Pathology and its Bias. J Cytol Tissue Biol 4: 014.

HP over the remaining gastric mucosal areas. Severe ulcerative gastric lesion at least will lose original HP density on account of partial erosion to total loss of mucosal layer, and may harbor nonspecific bacterial (Figures $5 \mathrm{~A} \& 5 \mathrm{~B}$ ) or even fungal colonization due to loss of local immunity.

'Trace' HP density can be a problem of pathological diagnosis, because it could be an easy way for interpreting unconfirmed HP morphology or a time consuming job to confirm a trace HP density but get an uncertain clinical significance for HP eradication treatment. Anyway, precipitates or striae of mucous covering without regular

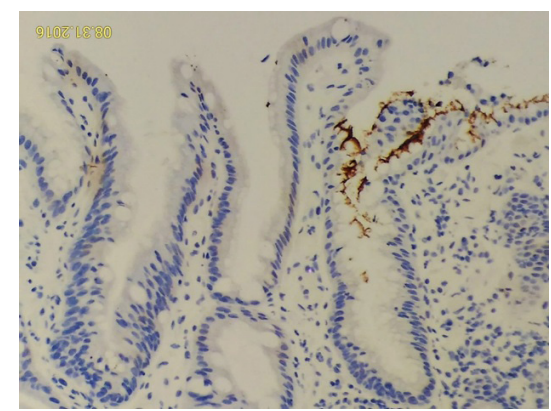

Figure 4: The intestinal metaplasia area is always devoid of HP density (left portion) (HP IHC stain, 400X).

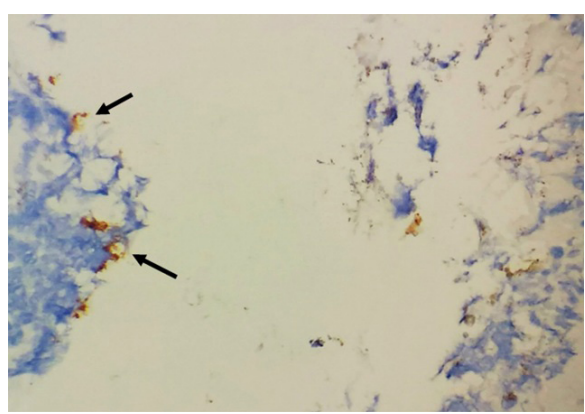

Figure 5A: Rare finding of smudge-patterned anti-HP immunostaining on ulcer surface (arrows), but devoid of HP density on nearby intact mucosa (not shown) (HP IHC stain, 400X). Coccoid bacteria with weak to negative HP immune staining well mixed with inflammatory exudate of ulcer on right upper portion may be a nonspecific bacterial colonization (other than HP) on necrotic tissue.

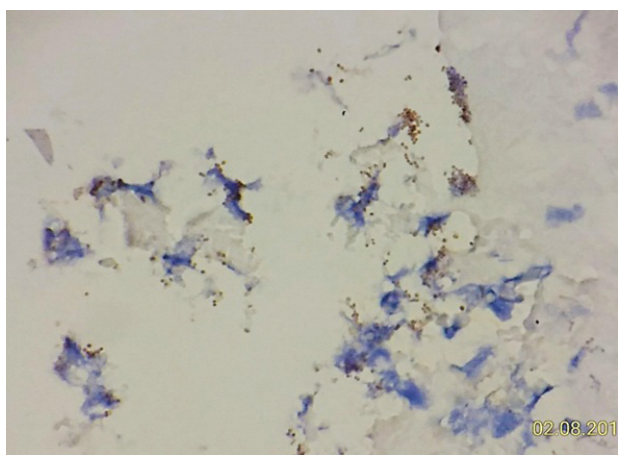

Figure 5B: A more magnified view of the coccoid bacteria (HP IHC stain, $600 X)$

bacterial contour, and neither gray staining for $\mathrm{H} \& \mathrm{E}$ stain nor dark blue staining for Giemsa stain should not be interpreted as low or trace HP density. Otherwise, these over interpretations of so called gold standard might reflect in appropriate lower sensitivity of other HP tests such as stool antigen test in some nations [16,17] comparing with that of another nation [18]. More expensive HP Immunohistochemical (IHC) stain can reduce false positive or false negative results dramatically [19]. Bacterial contamination in duodenal biopsy may also occur from the HP in gastric secretion or nonspecific bacteria on oropharyngeal mucosa. These false trace HP finding could be proved with ${ }^{13} \mathrm{C}$-urea Breath test [5], which detects more carbon dioxide breathed out after ingestion of urea-containing tablet. Medium HP density or high HP density has less controversy on pathological interpretation.

Endoscopic check up for upper gastrointestinal tract is routine for most hospitals. Tissue examination with CLO test is cheap and convenient, although for some reasons there are discrepant results comparing with the $\mathrm{H} \& \mathrm{E}$ stain or Giemsa's stain [20], that are partly caused by recognizing contaminated oropharyngeal bacterial as HP (Figures $6 \mathrm{~A}-6 \mathrm{E})$ or neglecting low HP prevalence by interpreter [21,22]. Nevertheless, false negative of invasive procedure for tissue examination related to sampling error from patchy HP distribution does occur (Figure 3A2) [5,23]. Additional test for any single negative or incompatible 'tissue' finding can improve the detection quality and interpretation experience via developed noninvasive tests for HP infection.

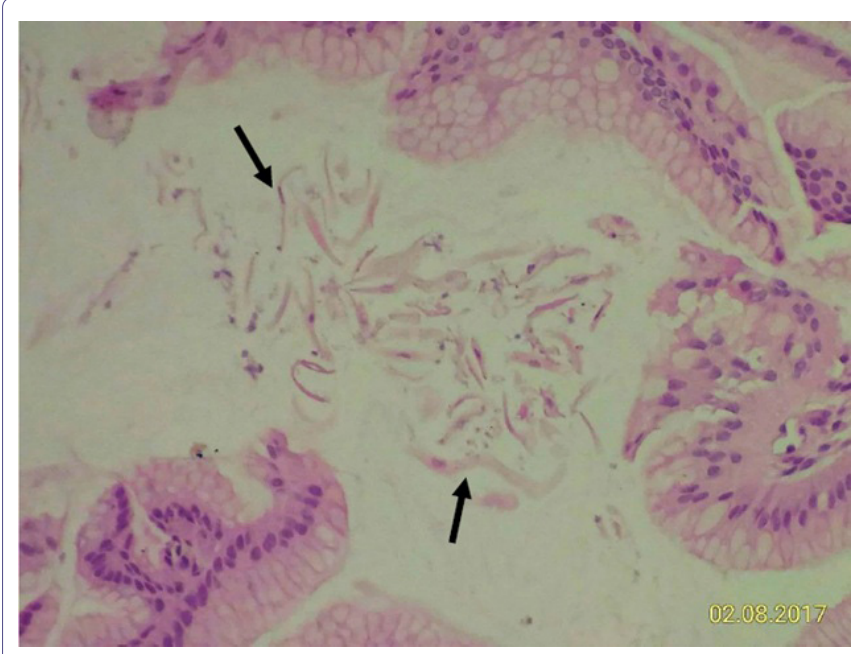

Figure 6A1: Some contaminated squamous epithelial cells (arrows) and bacteria from oropharyngeal tract are found on gastric biopsy (100x).

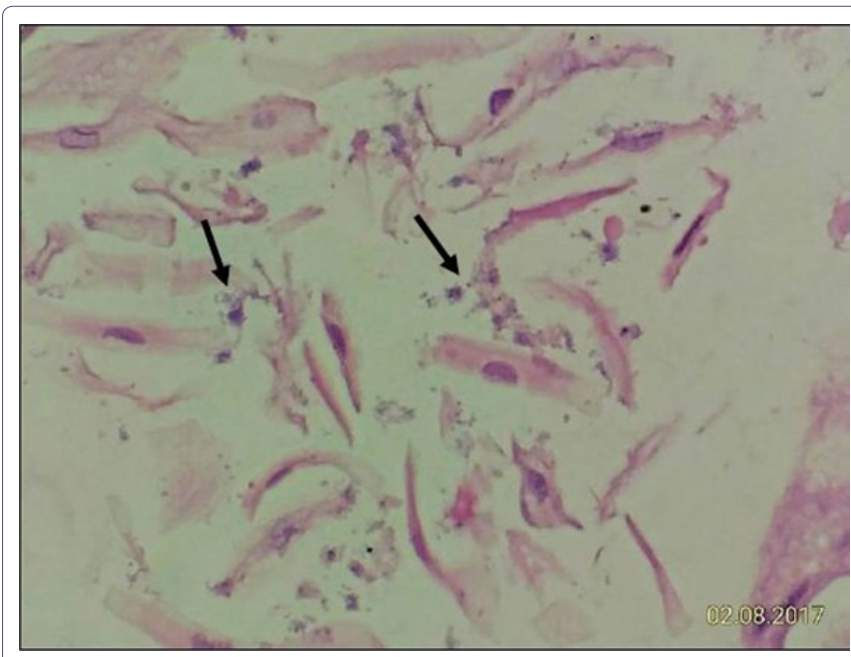

Figure 6A2: High power field can see the contaminated bacterial clumps (arrows) obviously (400X) 
Citation: Shih CM, Chueh WY, Chung TT, Liu CK, Liu CC, et al. (2017) Histological Interpretation of Helicobacter pylori Density Relevant to Gastric Pathology and its Bias. J Cytol Tissue Biol 4: 014.

- Page 4 of 5 •

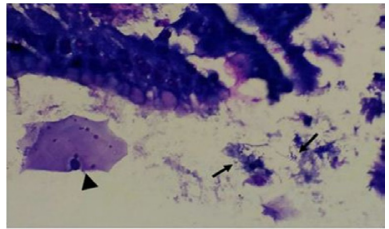

(B)

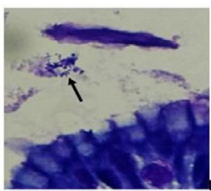

(B2)

Figure 6B (1,2): Giemsa stain shows contaminated cocci (arrows) in B1 and contaminated bacilli (arrows) in B2. We can see nearby oropharyngeal squamous epithelial cell (arrow head).

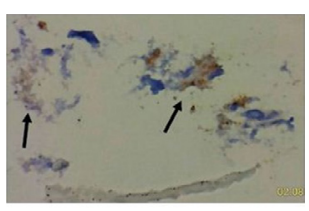

(C1)

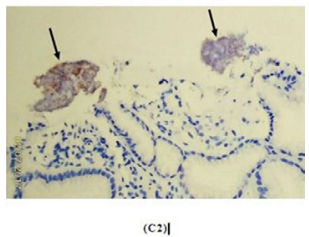

Figure 6C (1,2): HP immunostain on the large coccal bacterial clumps (arrows) show only partially or weakly positive immunostaining, and proved to be oropharyngeal contamination (400X).

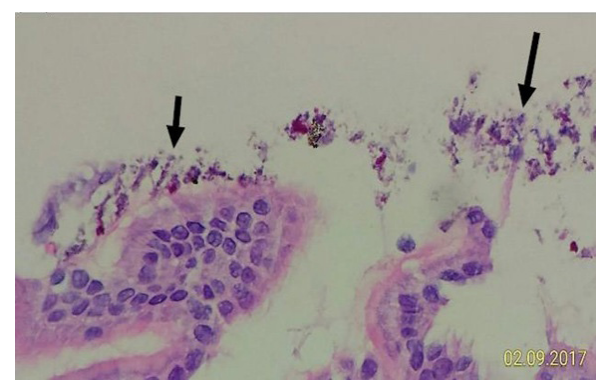

Figure 6D: Some contaminated bacteria can be pressed onto the mucosal surface intimately (short arrow) by biopsy forceps. However, the other part of contaminated bacteria and red foreign bodies are away from the mucosal surface (long arrow).

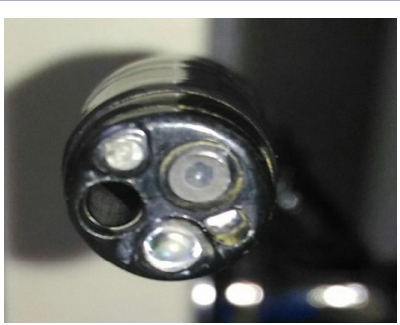

Figure 6E: Sharp edges on the tip of endoscope may scrape off some oropharyngeal bacteria and may contaminate the biopsy forceps and gastroduodenal tissue.

\section{Conclusion}

The tissue specimens from fundic gland polyp do not have the representative HP density for sampling. The prevalence of HP infection in human being should drop while most of the medical members have the concepts of HP impact. Suspicious histologic finding of HP density should add ancillary test such as ${ }^{13} \mathrm{C}$-urea Breath test or detection of HP antigen in stool for further confirmation.

\section{Acknowledgement}

It is grateful to have the help of expert English modification by our colleague Ms. Hui Ling Lin.

\section{References}

1. http://www.nobelprize.org/

2. Lee JY, Kim N (2015) Diagnosis of Helicobacter pylori by invasive test: histology. Ann Transl Med 3: 10.

3. Celli JP, Turner BS, Afdhal NH, Keates S, Ghiran I, et al. (2009) Helicobacter pylori moves through mucus by reducing mucin viscoelasticity. Proc Natl Acad Sci USA 106: 14321-14326.

4. Somily AM, Morshed MG (2015) An update of laboratory diagnosis of Helicobacter pylori in the Kingdom of Saudi Arabia. J Infect Dev Ctries 9: 806-814.

5. Malfertheiner P, Megraud F, O'Morain CA, Gisbert JP, Kuipers Ej, et al. (2016) Management of Helicobacter pylori infection-the Maastricht V/Florence Consensus Report. Gut 66: 6-30.

6. Wang YK, Kuo FC, Liu CJ, Wu MC, Shih HY, et al. (2015) Diagnosis of Helicobacter pylori infection: Current options and developments. World J Gastroenterol 21: 11221-11235

7. Faigel DO, Childs M, Furth EE, Alavi A, Metz DC (1996) New noninvasive tests for Helicobacter pylori gastritis. Comparison with tissue-based gold standard. Dig Dis Sci 41: 740-748.

8. Tseng CA, Wang WM, Wu DC (2005) Comparison of the Clinical Feasibility of Three Rapid Urease Tests in the Diagnosis of Helicobacter pylori Infection. Dig Dis Sci 50: 449-452.

9. Zagari Rm, Romano M, Ojetti V, Stockbrugger R, Gullini S (2015) Guidelines for the management of Helicobacter pylori infection in Italy: The III Working Group Consensus Report 2015. Digestive and Liver Disease 47: 903-912.

10. Frenck RW Jr, Fathy HM, Sherif M, Mohran Z, El Mohammedy H, et al. (2006) Sensitivity and specificity of various tests for the diagnosis of Helicobacter pylori in Egyptian children. Pediatrics 118: 1195-1202.

11. Shah DK, Jain SS, Mohite A, Amarapurkar AD, Contractor QQ, et al. (2015) Effect of $\mathrm{H}$. pylori density by histopathology on its complications and eradication therapy. Trop Gastroenterol 36: 101-106

12. Atherton JC, Tham KT, Peek RM Jr, Cover TL, Blaser MJ (1996) Density of Helicobacter pylori infection in vivo as assessed by quantitative culture and histology. J Infect Dis 174: 552-556.

13. D'Elios MM, Appelmelk BJ, Amedei A, Bergman MP, Del Prete G (2004) Gastric autoimmunity: the role of Helicobacter pylori and molecular mimicry. Trends Mol Med 10: 316-323.

14. Genta RM (2002) Review article: after gastritis--an imaginary journey into a Helicobacter-free world. Aliment Pharmacol Ther 4: 89-94.

15. Abraham SC (2010) Fundic gland polyps: common and occasionally problematic lesions. Gastroenterol Hepatol (N Y) 6: 48-51.

16. Sharbatdaran M, Kashifard M, Shefaee S, Siadati S, Jahed B, et al. (2013) Comparison of stool antigen test with gastric biopsy for the detection of Helicobacter Pylori infection. Pak J Med Sci 29: 68-71.

17. Syam AF, Rani AA, Abdullah M, Manan C, Makmun D, et al. (2005) Accuracy of Helicobacter pylori stool antigen for the detection of Helicobacter pylori infection in dyspeptic patients. World J Gastroenterol 11: 386-388. 
Citation: Shih CM, Chueh WY, Chung TT, Liu CK, Liu CC, et al. (2017) Histological Interpretation of Helicobacter pylori Density Relevant to Gastric Pathology and its Bias. J Cytol Tissue Biol 4: 014.

- Page 5 of 5 •

18. Choi J, Kim CH, Kim D, Chung SJ, Song JH, et al. (2011) Prospective evaluation of a new stool antigen test for the detection of Helicobacter pylori in comparison with histology, rapid urease test, (13)C-urea breath test, and serology. J Gastroenterol Hepatol 26: 1053-1059.

19. Miftahussurur M, Yamaoka Y (2016) Diagnostic Methods of Helicobacter py Iori Infection for Epidemiological Studies: Critical Importance of Indirect Tes Validation. BioMed Research International 2016: 4819423.

20. Seo JH, Youn HS, Park JJ, Yeom JS, Park JS, et al. (2013) Influencing Factors to Results of the Urease Test: Age, Sampling Site, Histopathologic Findings, and Density of Helicobacter pylori. Pediatr Gastroenterol Hepatol Nutr 16: $34-40$
21. Moayyedi $P$, Axon AT (1999) The usefulness of the likelihood ratio in the diagnosis of dyspepsia and gastroesophageal reflux disease. Am J Gastroenterol 94: $3122-3125$

22. Peleteiro B, Bastos A, Ferro A, Lunet N (2014) Prevalence of Helicobacter pylori infection worldwide: a systematic review of studies with national coverage. Dig Dis Sci 59: 1698-1709.

23. El-Omar EM, Oien K, El-Nujumi A, Gillen D, Wirz A, et al. (1997) Helicobacter pylori infection and chronic gastric acid hyposecretion. Gastroenterology 113 $15-24$ 